\title{
Overview of the techniques used for the study of non-terrestrial bodies: Proposition of novel non-destructive methodology
}

\author{
J. Aramendia ${ }^{\text {a, }}$, , L. Gomez-Nubla ${ }^{\text {a, }}{ }^{\text {, }}$, K. Castro ${ }^{\text {a, }}{ }^{\text {d }}$, S. Fdez-Ortiz de Vallejuelo ${ }^{\text {a, }}{ }^{\text {, }}$ \\ G. Arana ${ }^{\text {a, d }}$, M. Maguregui ${ }^{\text {a, d }}$, V.G. Baonza ${ }^{\text {b, d }}$, J. Medina ${ }^{\text {c, d }}$, F. Rull ${ }^{\text {c, d }}$, \\ J.M. Madariaga ${ }^{\text {a, d, * }}$ \\ a Department of Analytical Chemistry, University of the Basque Country (UPV/EHU), P.O. Box 644, E-48080 Bilbao, Spain \\ ${ }^{\mathrm{b}}$ Departamento de Química Física, Facultad de Ciencias Químicas, Universidad Complutense, E-28040 Madrid, Spain \\ c Unidad Asociada UVA-CSIC al Centro de Astrobiología, University of Valladolid, Parque Tecnológico Boecillo, E-47151 Valladolid, Spain \\ ${ }^{\mathrm{d}}$ Spanish Science Team of the RLS Instrument, Exomars 2020 Mission of ESA to Mars, Spain
}

\section{A R T I C L E I N F O}

Article history:

Available online 31 October 2017

\section{Keywords:}

Meteorites

Impactites

Spectroscopic techniques

Imaging techniques

Combination procedures

\begin{abstract}
A B S T R A C T
Meteorites and impact glasses have been largely analysed using different techniques, but most studies have been focused on their geological-mineralogical characterization and isotopic ratios, mainly of a destructive nature. However, much more information can be gained by applying novel non-destructive analytical procedures and techniques that have been scarcely used to analyse these materials. This overview presents some new methodologies to study these materials and compares these new approaches with the commonly used ones. Techniques such as X-Ray Fluorescence (XRF) and Laser Induced Breakdown Spectroscopy (LIBS), for elemental characterization, the hyphenated Raman spectroscopySEM/EDS and the combination of them, allow extracting simultaneous information from elemental, molecular and structural data of the studied sample; furthermore, the spectroscopic image capabilities of such techniques allow a better understanding of the mineralogical distribution.
\end{abstract}

() 2017 Elsevier B.V. All rights reserved.

\section{Introduction}

A meteorite is a solid natural object originated in the interplanetary space, from fragments of asteroids, comets and even other planets, which arrives through Earth's atmosphere [1]. Depending on the size of the meteorite, some of them can shock the surface of the Earth or even burst during the entrance through the atmosphere. Therefore, meteorites are composed of the original material of its source (i.e. asteroid, comet or planet) but their mineralogy and composition can vary due to the pressure and temperature conditions suffered during its travel, as well as eventual reactions with the materials at the place of arrival. Impact glasses or impactites, are terrestrial rocks or sediments that have been altered by the heat, pressure and shock waves associated with the impact of an airburst or a large meteorite. Thus, the study of all these materials is also crucial for the research of the Solar System,

\footnotetext{
* Corresponding author. Department of Analytical Chemistry, University of the Basque Country (UPV/EHU), P.O. Box 644, E-48080 Bilbao, Spain.

E-mail address: juanmanuel.madariaga@ehu.eus (J.M. Madariaga).
}

since fragments of the original bodies remain trapped in the glass. Besides, as they have been wandering through the space for a long time, they also may act as historic tracers. This last fact could also help to understand the origins of the Earth [2].

The human being has been interested in the composition of these non terrestrial bodies and analogues since the early 1800's. Around 1820 some works were published [3] containing elemental analysis of, for example, vanadium, nickel or iron. Even though their concentrations were obtained by tedious titrations, this kind of analysis was still carried out until the end of the 19th century [4]. From the molecular point of view, the first studies were performed in the mid 19th century with not very good results [5].

Fortunately, analytical methods have evolved towards more reliable and sensitive techniques and, nowadays, they allow performing deeper and sophisticated analyses in order to identify the elemental and molecular composition. This information is crucial for the elucidation of many questions that are still unanswered. Analysis of meteorites and other non-terrestrial bodies are also very valuable for inferring the composition of the non-terrestrial body origin (planet, asteroid, etc.), the conditions of pressure and temperature of the meteorite arrival, signs of water presence and 
more. They could even be very useful in the field of knowledge of Materials or Geology since in meteorites new minerals [6,7] could be discovered that could not be formed under terrestrial conditions. These new minerals could be potentially useful in our lives, for instance as superconductors [8].

Apart from the study of the origin and composition of the meteorites, the last published studies have been focused on the searching of organic compounds related or not with the life in other corners of the Solar System [9-12]. In the majority of these cases, the analyses have been carried out using gas or liquid chromatography with their respective sample preparation, which implies material consumption (both extraterrestrial samples and chemicals) in all cases.

Being this the state-of-the-art, the elemental and molecular analyses are very important in the research of these materials and, above all, the use of non-destructive techniques, in order to preserve these valuable samples. Unfortunately, destructive analytical techniques have been used in most of the analyses of meteorites. Therefore, with this work, the historical analytical procedure for the analysis of meteorites and analogues is reviewed and, after identifying the pitfalls and drawbacks of the existing methodologies, a combined non-destructive analytical procedure for the exclusive analysis of meteorites is proposed. By means of this procedure an almost complete characterization of the nonterrestrial materials can be performed.

\section{Destructive techniques used for meteorite analyses}

As mentioned before, many of the research works published during the last decade on analytical techniques applied to meteorites analysis are based on the use of destructive or semidestructive techniques.

For example, ICP-MS (Inductively Coupled Plasma-Mass Spectrometry) or ICP-AES (Inductively Coupled Plasma-Atomic Emission Spectroscopy) have been used in this field for the elemental characterization. These techniques have been usually applied to the quantification of rare earths and metals [13], especially iron, since it is one of the most abundant elements in the whole Solar System [14]. However, the use of this destructive and sample consuming method is decreasing. These kind of techniques are highly sensitive (in the order of $\mathrm{ng} \mathrm{g}^{-1}$ ) and they can be used to perform routine analyses quantifying as many analytes as are needed at the same time. This notwithstanding, as in other matrices, there are many interferences among the elements, and the analysis have to be optimized to avoid them [14]. Moreover, as the samples are solid, they must be dissolved and analytes extracted by using usually aqua regia $\left(\mathrm{HCl}\right.$ and $\left.\mathrm{HNO}_{3}\right)[13,14]$. However, it must be pointed out that silicates are not totally dissolved, thus, the extraction is not total. Silicates are one of the main components of meteorites; hence a lot of information is lost. This could lead to wrong interpretations of the ICP-MS/AES data. In some works [15] $\mathrm{HF}$ is used together with $\mathrm{HCl}$ and $\mathrm{HNO}_{3}$, but this acid is extremely dangerous and its handling must be carried out with great care following strict safety protocols. Alternatively, alkaline fusion can be used for the total dissolution of the matrix. However, in some cases the pre-treatment still needs a consecutive acid extraction using HF [16].

Infrared spectroscopy also has been applied in the study of meteorites and impact glasses. For example, it has been used for the determination of hydrated mineral forms since it is one of the few techniques which can detect $-\mathrm{OH}$ and $\mathrm{H}_{2} \mathrm{O}$ groups [17]. This application can be very useful nowadays because the main goal of most of the upcoming Mars missions is to find water or hydrated minerals. The results obtained in the works where infrared spectroscopy was applied for the searching of water were successful
[18] in the identification and characterization of bound water or hydroxyl bonds in mineral phases and hydrated compounds in meteorites.

In some works $\mathrm{KBr}$ pellets are prepared for the analyses in transmittance mode [17] involving the destruction of the original sample. However, the pellet can be preserved for the future. In other configuration such as absorbance or ATR, samples have to be grinded to powder.

Finally, X-ray Diffraction (XRD), which allows extracting molecular and structural information, has been used for the study of non-terrestrial samples. For example, it has been used to see differences in major mineral phases present in meteorites due to differences of pressure [19]. This technique is well recommended to probe the phase transitions that can occur during the impact ejection, successive impacts through the space or the impact of arrival of the meteorite. Nevertheless, Tilley et al. [20], described some disadvantages of using XRD in meteorites. For example, if amorphous or Poorly Diffracting Materials (PDM) are present in the sample, there is no diffraction signal or it is so poor that the signal is indistinguishable from the noise. Besides, this technique requires prior milling of the sample and its subsequent consumption.

All described techniques are very useful, and important information can be obtained from studied samples. Unfortunately, they consume material or destruct, at least partially, the samples during the analysis. For this reason, the so-called non-destructive and noninvasive techniques acquire a great importance since they do not damage the analysed samples [2]. Due to the high economic and scientific value of the samples, it is much more appropriate to preserve their integrity as much as possible.

\section{Non-destructive techniques applied to meteorites study}

There are many non-destructive techniques used for biogeochemistry research and many of them have been applied to the study of non-terrestrial bodies. In this section, the most relevant ones are described.

\subsection{Elemental analyses}

Several elemental non-destructive techniques have been used for analysing the composition of meteorites. Particle-Induced X-ray Emission (PIXE) or micro-PIXE is an elemental technique that does not need any special sample pre-treatment. It allows identifying and quantifying in a single analysis several elements. The more recent works using micro-PIXE in meteorites have been focused on very diverse objectives [21], such as the characterization of meteorites and their inclusions [22,23], which result interesting since in these little portions of meteorites and impact glasses, important features such as gases coming from the atmospheres or metallic inclusions, are trapped. PIXE maps can be obtained as shown by Bailey et al. [24] in inclusions of impact glasses called Darwin Glass, although they concluded that PIXE was not easily used to characterize the micro-inclusions, and that the used method was only qualitative and had poor depth resolution. In fact, its use has decreased with time as nowadays there are better non-destructive techniques in the market, despite the fact that last works highlight the great capability of micro-PIXE [22].

SIMS (Secondary Ion Mass Spectrometry) or nanoSIMS has been often used during the last decade for the study of the Solar System through meteorites, asteroids and others. Due to the high sensitivity and mass resolution, SIMS and nanoSIMS are appropriate tools for isotope analysis. Regarding this field, they have been applied for several aims, such as dating meteorites using different isotope ratio [25] and searching water in other planets [26,27]. SIMS and nanoSIMS are very useful in this field since they are very 
suitable for trace analysis. Moreover, elemental isotopic ratio images can be also obtained with SIMS [28]. Actually, the combination of SIMS with other devices has been applied to perform high precision isotope ratio imaging of micro-scale with high mass resolution (isotopography). By this way, it was possible to find a chemically and isotopically anomalous material (new PCP, Poorly Characterized Phase) from a meteorite [29].

Another elemental non-destructive technique used commonly for meteorite analyses is the X-ray fluorescence spectroscopy (XRF). XRF is an easy-to-handle technique for which no pretreatment or a minimum pre-treatment of the sample is needed. As an example of its applicability, the method developed in 2001 by Wolf et al. [30] for the analysis of small quantities of meteorite samples can be mentioned. The mentioned method was based on the preparation of the samples in glass disks, melting them, quantifying by the standard addition method. This approach was used later in 2012 by Stracke et al. in order to analyse the Allende meteorite [31]. The drawback of this method lies on the fact that a pre-treatment of the sample is needed and, therefore, the nondestructive nature of the technique is lost. In contrast, one year before, Aramendia et al. [32] had performed non-destructive $\mu$ XRF analyses of some impact glasses, called Libyan Desert Glass, carried out directly on the sample without any pre-treatment, using collimators to analyse areas from 0.2 to $1.5 \mathrm{~mm}$ in diameter. In addition, a new work has been recently published with semi-quantitative data using portable XRF device [33] to characterize an impact glass. Finally, a very interesting work was presented in the 43rd Lunar and Planetary Science Conference 2012 [34], where a XRF spectra library devoted to meteorites was presented. In that work, the most characteristic elements for each different group of meteorites were established, and through chemometric analysis, they were able to classify meteorites that were impossible to identify only by usual examination. Recently, a work has been published [35] where nanoscopic XRF images were acquired for meteorites study; large sections of meteorites can be analysed in the search of trace element concentrations plotting the results as a map in order to see the elemental distribution in the sample matrix. For instance, the elemental composition sometimes changes in the matrix depending on their atomic mass, and some elements can be found concentrated only in inclusions as occurred in Libyan Desert Glass samples (Fig. 1). For these cases, $\mathrm{XRF}$ images are the most suitable way to present the results. These images can be constructed using the area of the $K_{\alpha}$ line for each key element, employing appropriate software (as in the case shown in Fig. 1, where the Artax software by Bruker was used) and these values can be plotted using a kriging software to obtain the image.

More general idea of the sample composition as estimation of mass balance (\%) and element distribution is sometimes needed as a first step for its characterization. This kind of analysis was carried out on meteorites by our research group by using an X-Ray fluorescence system. The equipment used allows obtaining elemental distribution maps performing a fast elemental analysis using a mechanic collimator of $1 \mathrm{~mm}$ X-Ray spot size. The obtained elemental image of the sample (meteorite or impact glass) has a size of around $10 \mathrm{~mm}$ and is acquired in only $5 \mathrm{~h}$. Besides, the XRF spectrometer includes a vacuum chamber to be able to perform the analysis of light elements.

The software implemented in this equipment allows obtaining an estimation of phases based on the correlation among elements detected in each pixel of the elemental chemical image. With this data, the software can build a phase estimation image (see example on an EETA79001 in Fig. 2), which facilitates largely the further molecular characterization. Fig. 2 shows that the meteorite is formed by two different main phases, P1 and P3; the former is characterized by the presence of $\mathrm{Si}$, Fe and $\mathrm{Ca}$, the latter, in contrast, is characterized by the presence of Fe mainly.

On the other side, hand-held XRF devices are increasingly used $[33,36]$. This kind of devices is very useful because they allow performing easy and quickly (semi-) quantitative measurements of the samples. However, the use of these devices is very limited because it is not possible to perform micro-analysis and XRF images cannot be acquired.

XRF and PIXE have been used combined in a device so-called APXS (Alpha-Particle X-ray Spectrometer) [37]. It was developed for its implementation in some Mars Exploration Rovers (MER), such as Spirit and Opportunity in 2007 as well as Curiosity in 2011. APXS together with a camera and other spectrometers (Mossbauer and thermal emission spectrometer) were the responsible for, literally said by Campbell et al. [38] "major advances in the understanding of the Martian surface, especially as regards the prior existence of water on that planet". Actually, such was the success that APXS is part of the Mars Science Laboratory (MSL) mission, currently working in Mars since 2012, and some APXS developments are thought for future missions.

Regarding elemental analysis at micrometric scale, Scanning Electron Microscopy-Energy Dispersive X-ray Spectroscopy (SEMEDS) meets all the needs that are expected for an analytical tool used in the research of non-terrestrial bodies when searching at less than $1 \mu \mathrm{m}$. It does not destruct neither consume the sample during the analysis, although sometimes some previous preparation of the sample is needed for obtaining better images and performing better EDS analysis. It is very common to prepare thin or thick sections from the sample [39] and coat them with carbon [40] or gold. However, there are also some cases in which the specimens are directly analysed, for example, in order to search for bacteria in meteorites since if the samples are polished, life signs could be destroyed [41]. If a metallic meteorite is studied by SEM-EDS the coating is not needed.

This technique allows obtaining high resolution chemical images of selected areas of the analysed surface and it also provides semi-quantitative information. Therefore, it is possible to see the distribution of the elements in the bulk and to semi-quantify them [42]. All this information is crucial in order to determine the shock and thermal history, and finally the origin of meteorites. SEM-EDS has been commonly used following these aims [40,42,43]. This technique has been used in the search of signs of water in Mars, characterizing minerals that could have water of crystallization or possible alteration products that would be formed due to the presence of water in Mars [26,44]. However this technique is always used as supporting method to facilitate further analysis or to confirm them. It has been never used alone in meteorites analysis because more information than that provided by SEM-EDS is always needed, such as quantitative determination or molecular characterization.

Like the EDS, the electron microprobe analyzer (or EPMA) provides high-resolution elemental analysis on spots of $1-2 \mu \mathrm{m}$. This is one of the most important analytical tools in Earth sciences and it has been used for quantitative analyses of meteorites for decades [45]. Normally, it is used for characterization supporting its results with other techniques. However, there are strict requirements regarding sample preparation for obtaining good results. For instance, very thin preparations should be obtained from the sample, which means that the sample must be altered. Moreover, the surface of the preparation must be perfectly polished.

The non-destructive elemental techniques described are very useful for meteorite analyses and they have provided important results to understand better the universe and the Earth. However, they present an important drawback since most of them are not 

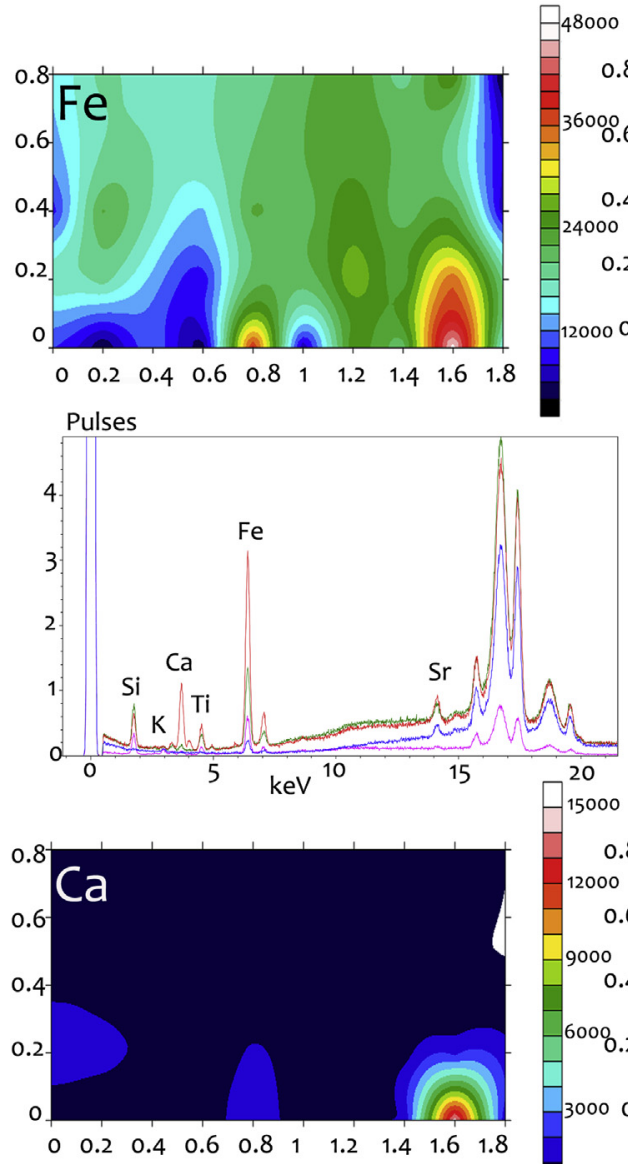

$-15000$
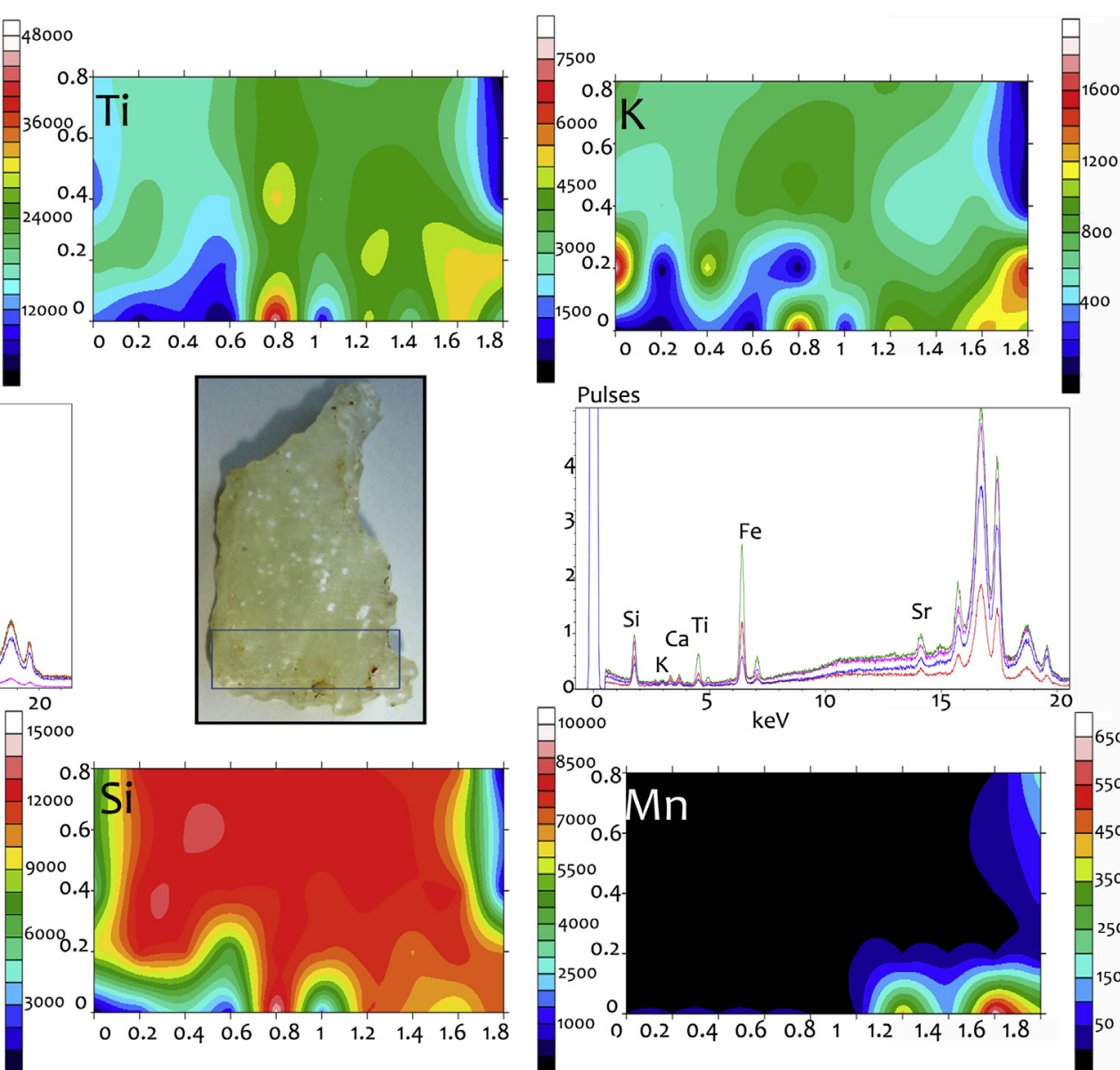

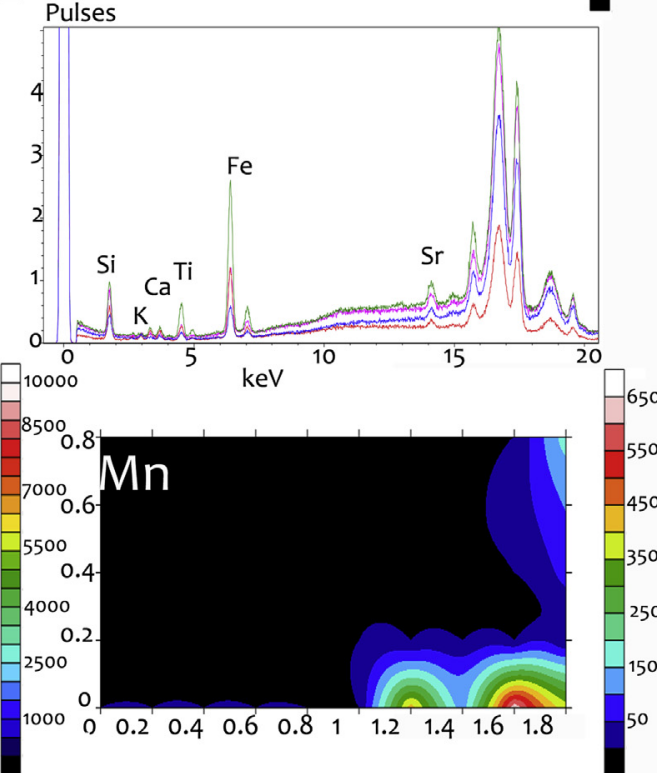

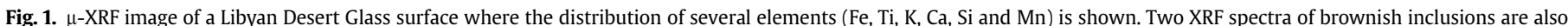
displayed showing the changes of the relative proportions (area) of $\mathrm{Si}, \mathrm{K}, \mathrm{Ca}, \mathrm{Ti}$ and $\mathrm{Fe}$.

very sensitive for light elements $[23,46]$. Due to this fact, LaserInduced Breakdown Spectroscopy (LIBS) is becoming a very important tool in the meteorites research field. One of the characteristics that differentiate this technique with those mentioned above is that LIBS is very sensitive for light elements such as $\mathrm{H}, \mathrm{Li}, \mathrm{B}$, $\mathrm{C}, \mathrm{N}$, and $\mathrm{O}$ [47]. For the detection of these elements, and in order to avoid atmospheric input, ideally, the analysis should be performed under vacuum conditions. However, this is not always possible but
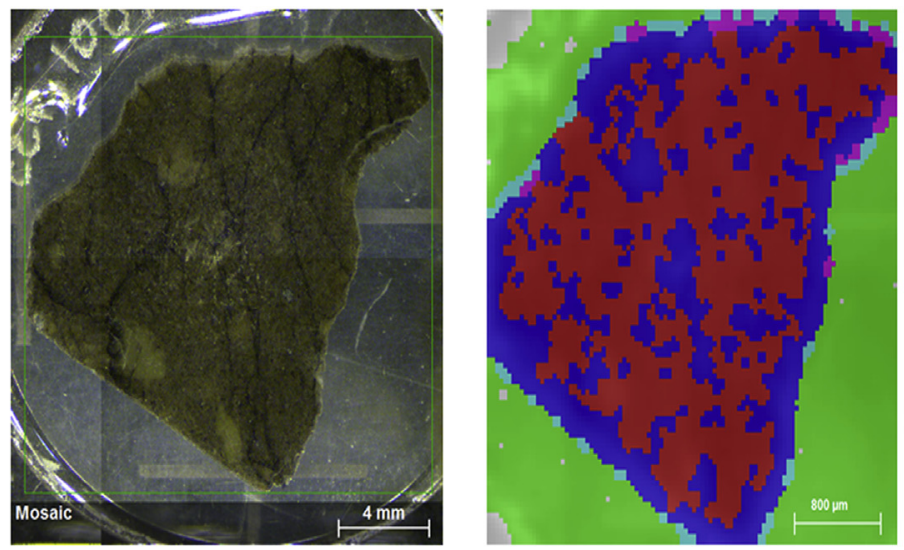

\begin{tabular}{|c|c|c|c|c|c|c|c|c|c|c|c|c|c|c|c|}
\hline $\begin{array}{l}\text { Mass-\% } \\
\text { (norm.) }\end{array}$ & $\mathrm{Mg}$ & $\mathrm{Ca}$ & K & V & $\mathrm{Ti}$ & Mn & $\mathrm{Cr}$ & $\mathrm{Fe}$ & $\mathbf{N i}$ & $\mathrm{Zn}$ & $\mathrm{Sr}$ & $\mathbf{S}$ & $\mathbf{P}$ & $\mathrm{Si}$ & Al \\
\hline P1 (red) & 0.09 & 6.77 & 0.14 & 0.06 & 0.42 & 0.73 & 0.51 & 63.4 & 0 & 0 & 0.05 & 0.54 & 1.85 & 25.01 & 0.36 \\
\hline P2 (green) & 0 & 20.35 & 8.39 & 1.6 & 1.97 & 2.22 & 1.77 & 6.02 & 2.23 & 2.96 & 9.53 & 1.09 & 0.39 & 0.43 & 0.01 \\
\hline P3 (blue) & 0 & 5.66 & 0.41 & 0.11 & 0.43 & 1.09 & 0.7 & 80.5 & 0.06 & 0.13 & 0.37 & 0.6 & 1.19 & 7.02 & 0.06 \\
\hline P4 (turqoise) & 0 & 11.65 & 3.31 & 0.81 & 1.53 & 2.57 & 1.44 & 50.5 & 0.9 & 1.57 & 3.79 & 0.66 & 0.26 & 1.15 & 0.18 \\
\hline P5 (pink) & 0 & 10.3 & 1.89 & 0.35 & 1.11 & 2.34 & 1.11 & 63 & 0.44 & 0.88 & 1.94 & 0.99 & 1.36 & 4.1 & 0.26 \\
\hline
\end{tabular}

Fig. 2. Phase estimation image created by M4 TORNADO on a thick sample of the EETA 79001 meteorite specimen. 
it can be solved carrying out a blank and subtracting the atmospheric input.

LIBS offers other benefits such as ease-of-use, no need to pretreat the sample, robustness and versatility. Nevertheless, the use of the laser has also some drawbacks. For instance, it is considered micro-destructive due to the crater that it leaves after each laser pulse with the corresponding removal of part of the sample. This notwithstanding, it only consumes few nanograms of material per pulse [47] on a surface around $200 \mu \mathrm{m}$ in diameter.

The LIBS technique also allows performing quantitative analysis of major, minor and trace elements present in the meteorites samples. Actually, some studies state that, by means of LIBS, it is possible to quantify some trace elements which are impossible to detect or quantify by other techniques such as ICP-MS or XRF [48]. Moreover, the quantification using LIBS differs from others, such as AAS (Atomic absorbance spectroscopy) or ICP-MS, in the fact that sample dissolution is not required. Therefore, no reactants are used, there is no sample consumption, contamination is avoided and all this makes it an inexpensive and appropriate method for the study of the meteorites and impact glasses. In addition, Veis et al. [49] applied a calibration-free method for meteorites based on the electron concentration and temperature. Calibration-free method means that no reference standard material is needed and that the elemental quantification is performed without using calibration curves. This fact provides more advantages as sometimes finding the most suitable reference material supposes an arduous work since the compounds present in meteorites are very diverse [50].

LIBS has become one of the techniques selected for the Mars exploration missions [50,51]. It was mounted on the Curiosity rover inside the ChemCam instrument [52], and soon, it will be part of the next NASA Mars Mission 2020 [53].

There are several reasons for selecting LIBS technique for these missions. The first one is that the analysis can be performed remotely without the need of being in contact with the sample. It can determine the composition of a soil or target rock from more than $6 \mathrm{~m}$ [53]. Moreover, in the Mars surface there is a lot of dust that can hinder the analysis. However, laser pulses emitted by the LIBS remove all the dust from the surface and make the posterior analyses easier.

Although it has been said that it can be considered microdestructive, the crater left by the laser pulses in the surface of the sample results useful because the more that the laser incises on the sample the deeper the crater is. In this way, depth analysis can be also carried out as the crater goes down with each pulse. This kind of analyses are very useful in Mars surface to research on weathering processes that change the surface and to identify the raw soil and compare it with historic evidences that are reflected in the different layers of the soil.

In addition, it is possible to perform LIBS analysis under extreme conditions, for example at low atmospheric pressure [48], which is interesting to reproduce in the laboratory the conditions present in the space.

It is worth pointing out that even if most of the ICP-MS are considered to be destructive, laser-ablation inductively-coupledplasma mass spectrometry (LA-ICP-MS is said to be almost nondestructive. Apart from that, it offers all the advantages of the ICP-MS, like low detection limits, accuracy and rapidity, without sample pre-treatment [54]. In fact, it is said to replace XRF. It is usually used for isotopic and trace analyses [55] of metals and rare earths in meteorites.

\subsection{Molecular analyses}

There are several non-destructive techniques that provide molecular composition. One of the most popular molecular analytical techniques for the study of meteorites is Mössbauer spectroscopy. Mössbauer has been applied since two decades ago, mostly, for the study of metallic, iron based meteorites or their iron inclusions because it gives information about the atomic environment of element nuclei, and therefore, it is possible to identify the composition of the sample together with the molecular structure [56]. Moreover, it is also possible to perform quantitative analyses of different mixtures of iron phases as in an iron meteorite analysed by the Opportunity rover directly in Mars [57]. Of course, nowadays, other non-destructive techniques are able to carry out this quantification. However, what makes the difference with Mössbauer spectroscopy, in the special case of meteorites, is that several $\mathrm{Fe}-\mathrm{Ni}$ compounds such as taenite $(\gamma-(\mathrm{Fe}, \mathrm{Ni}))$ or kamacite $(\alpha-(\mathrm{Fe}, \mathrm{Ni}))$ are difficult to detect or identify with other molecular techniques such as Raman spectroscopy.

As has been mentioned before, even if sometimes infrared spectroscopy can be considered destructive, there are several configurations to perform infrared measurements in a non destructive way. In recent works infrared imaging analysis of meteorites has been carried out [58]. This approach resulted appropriate for the study of the compounds distribution in the nonterrestrial bodies. The distribution of some compounds could give many clues about the origin and the processes that the sample experimented [59], therefore, the distribution study could be a key for elucidating important questions. Besides, the sample is not consumed and can be used for further analysis.

The upcoming ESA and NASA missions to Mars (EXOMARS 2020 and MARS 2020 respectively) will carry near infrared spectrometers in their respective rovers $[60,61]$. The final objective of the infrared devices is to perform mineralogical and organic characterization of the Mars surface and to find water related compounds (bearing $-\mathrm{OH}$ or water) or aqueous alteration clues.

One of the most important techniques for molecular analyses of non-terrestrial bodies, if we take into account the number of publications, is Raman spectroscopy [62-66]. Raman spectroscopy is rather similar to Infrared spectroscopy since both provide structural and molecular information about the analysed sample. However, with Raman spectroscopy no pre-treatment of the sample is required whatever the configuration is. Moreover, there is the possibility to work with different wavelength lasers, even in the same device. Each wavelength could fit the sample better than other, giving better or worse results, depending on the kind of meteorite or impact glass. For instance, with the $785 \mathrm{~nm}$ laser in the case of vitreous matrices, luminescence phenomena could appear. This phenomenon appears in silicate glasses with low quantities of heavy metals or rare earths in the structure. Due to this fact, very intense and broads bands appear between 1200 and $1800 \mathrm{~cm}^{-1}$. These bands, considering their size, sometimes shield or overlap other Raman signals, hiding molecular information. This fact can be a considerable problem although it is easy to solve changing the laser wavelength, since with others, such as $514 \mathrm{~nm}$ laser, this phenomenon is avoided (Fig. 3).

Furthermore, sometimes when analysing this kind of materials fluorescence could be present in the spectrum shielding the sample characteristic Raman signals. However, as occurred with luminescence, this fact can be solved by changing the excitation laser [67].

Even if Raman spectroscopy is not considered a quantitative technique, quantitative works on meteorites have been published by using the position, height, area or other features of Raman bands [62,66,68]. Quantitative analysis on meteorites was applied by El Amri et al. [64] for the study of organic molecules using Surface Enhanced Raman Spectroscopy (SERS). Actually, signal enhancement by using nanoparticles is another advantage that Raman spectroscopy offers. This modified Raman approach allows intensifying the signal of traces present in the sample by the addition of 

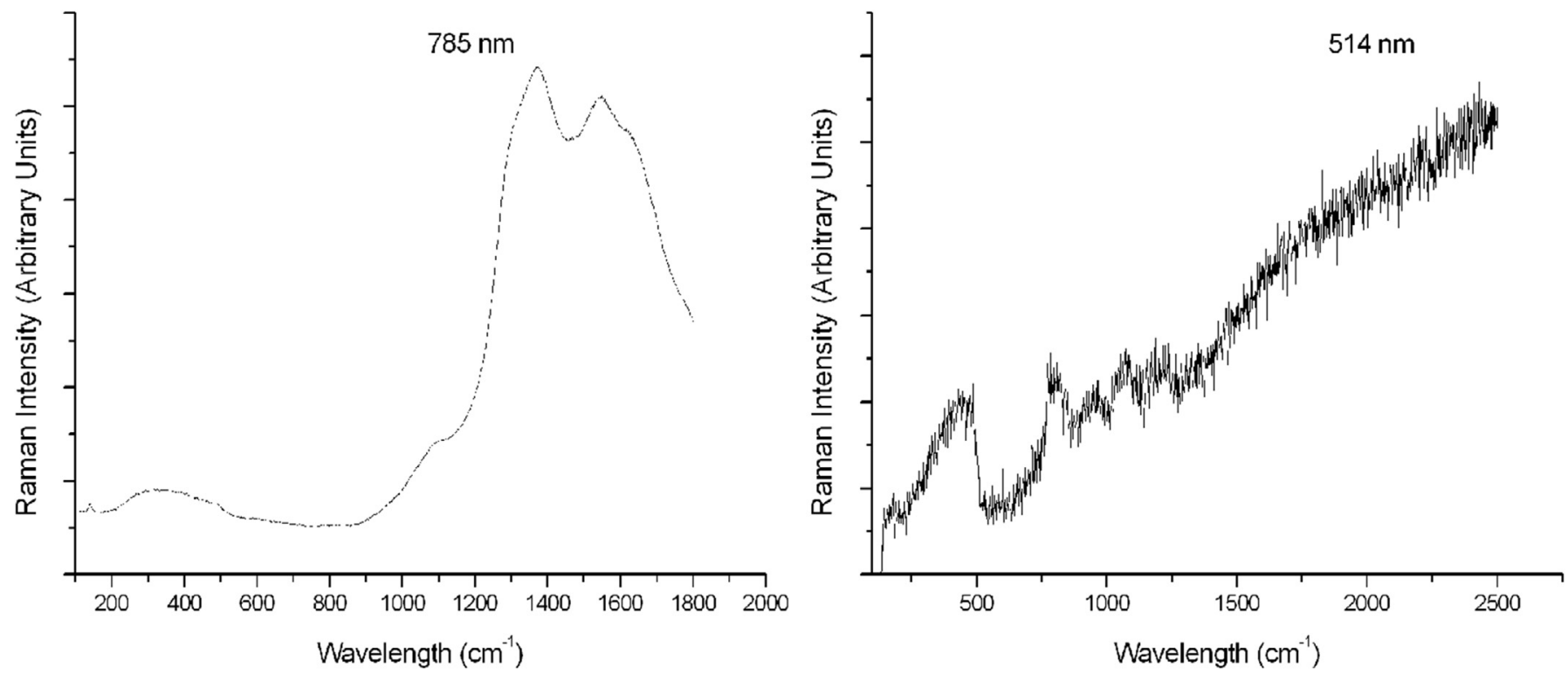

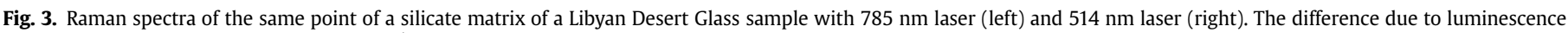
phenomenon is clear in the $1200-1800 \mathrm{~cm}^{-1}$ range.

certain nanoparticles. However, SERS has not been widely applied in this field. Indeed, it has been only used for the identification of organic compounds such as adenine in meteorites [65]. SERS also reduces the fluorescence of the sample.

Another advantage of this technique coupled with the confocal microscopy is the capability to perform depth profiling analysis without the need of cutting or slicing the sample. In the reviewed field, this alternative technique is the key for the analysis of bubbles, which are cavities in the matrix of the meteoroids filled by liquid or gases. The characterization of the bubbles present in nonterrestrial bodies helps in the characterization of other atmospheres and the better comprehension of the procedures that the non-terrestrial body experiences just before falling on Earth. Moreover, slicing the meteoroids makes the analysis of the bubbles difficult since if a bubble is cut, the gases that it contained escape (Fig. 4) [17]. Therefore, confocal Raman spectrometry is the unique non-destructive technique able to face this task. In addition, Raman microscopy allows performing imaging analysis by carrying out Raman mapping (Fig. 5). This procedure has been largely applied to the study of meteorites and analogues [59,67,69]. As described for infrared imaging, the application of this Raman set-up is useful for the study of the distribution of the different compounds in the analysed samples and the distribution correlations of the compounds among each other.

As occurred with some of the techniques mentioned in this work, Raman has been also selected to be used in some of the missions to other planets. Actually, it will be present in the rovers of EXOMARS 2020 and MARS 2020 missions. The aims defined for this device in both missions are to identify and characterize both mineral and organic compounds in the Mars surface and always with the final objective of detecting present or past signs of life $[60,70]$. In both cases they will be equipped with a $532 \mathrm{~nm}$ wavelength laser, to avoid luminescence phenomena. It must be taken into account that biological organic compounds or biomarkers such as carotenoids or oxalates are only identified with that wavelength in most of the cases [71].

It is worth highlighting that by the exclusive use of a combination of non-destructive techniques, an absolute complete study can be carried out, as demonstrated recently by Garcia-Guinea et al. [39]. In that work, a complete qualitative and semiquantitative characterization of a meteorite was performed for the first time using exclusively non-destructive techniques such as XRD on flat surface (without the need of grinding the sample), Raman spectroscopy and EPMA. In this way, for the first time,

a)
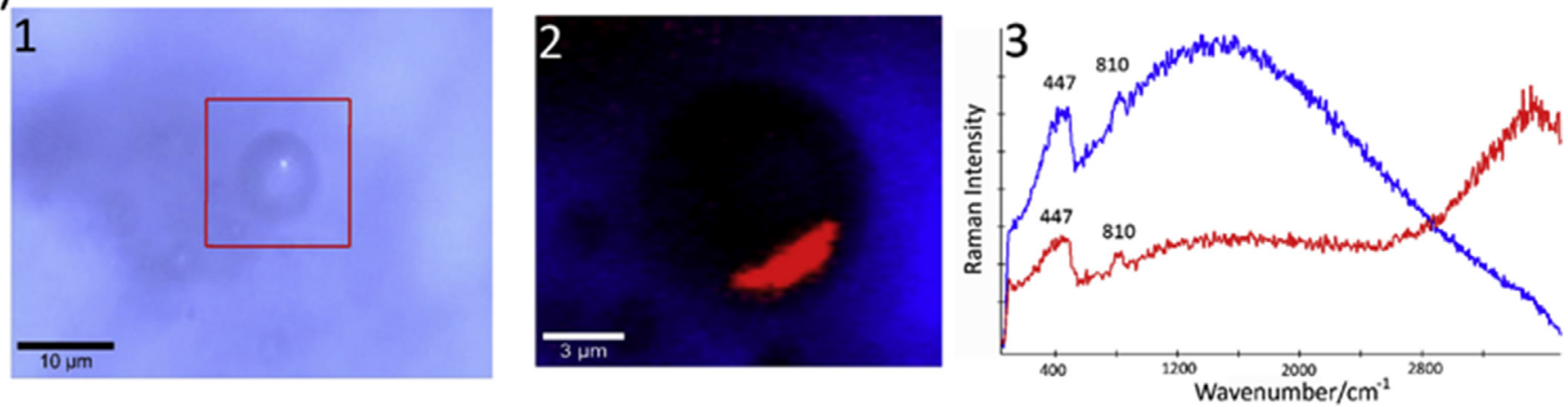

Fig. 4. Raman confocal analysis for the characterization of air bubbles in Libyan Desert Glass samples. Unfortunately, it was a slice preparation and the bubbles were empty. 

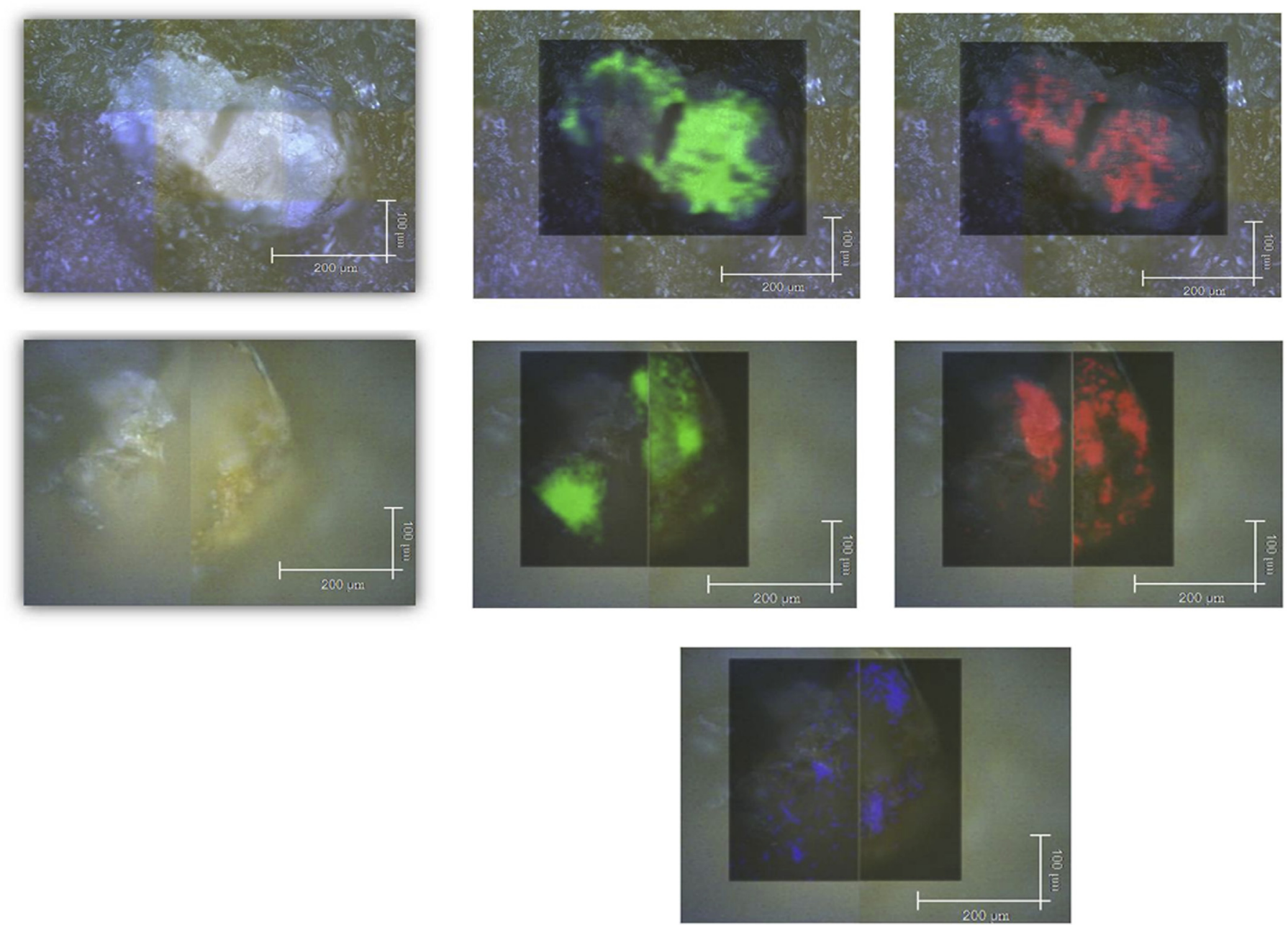

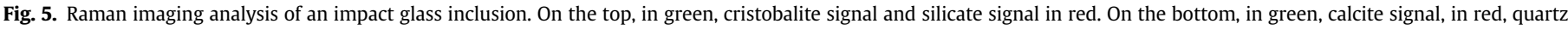
signal and haematite signal in blue.

semi-quantitative mineral percentage was defined for the studied meteorite.

\section{Proposed methodology}

Taking into account all mentioned above a complete nondestructive methodology for the deep characterization and study of this kind of materials will be proposed. This methodology includes elemental and molecular-structural complete characterization, element and compounds distribution study and elemental and compounds semi-quantification and it is carried out by both elemental and molecular techniques using image and punctual configurations.

First of all, XRF and Raman images would be collected to obtain a general view of the distribution of elements and compounds in the sample. Regarding Raman spectroscopy, it is advised to use the 532 or $514 \mathrm{~nm}$ laser to avoid luminescence phenomena.

Once a general scheme of the sample has been constructed, point-by-point analyses can be carried out for improving the resolution both by XRF and Raman spectroscopy. For the light elements, the employment of LIBS is recommended if microcraters of around $200 \mu \mathrm{m}$ in diameter are allowed on the surface of the samples, since, unlike XRF, $\mathrm{H}, \mathrm{Li}, \mathrm{N}, \mathrm{O}$ and $\mathrm{C}$ can be detected and quantified if required. Therefore, with the combi- nation of these two techniques all the important elements would be covered. In addition, LA-ICP-MS is proposed in order to perform isotopic analysis, very useful for determining the origin of the samples, and to quantify traces of metals and rare earths since the limit of detection of the technique is lower than the XRF.

Finally, in order to complete these studies, a novel technology very suitable is introduced.

As has been mentioned above, several techniques are frequently combined with others for completing the characterization of the samples. This is the case of the combination of Raman (micro) spectroscopy) and SEM/EDS (Raman-SEM/EDS), which gives very successful results in the characterization of meteorites and analogues. However, the simultaneous use of both devices is not always easy or even possible to perform because once the analysis of an area of interest by SEM/EDS is carried out, then, to find and analyse the same microscopic area by means of Raman microscope is arduous. To avoid this problem, the Raman-SEM/EDS interface was developed (there is the commercial trademark SCA, Structural and Chemical Analyzer, from Renishaw that first introduced this instrument). This technique is so innovative that no publications regarding its use in meteorites and impact glasses have been found and it has been applied in only some works with other matrices $[72,73]$. 
This Raman-SEM/EDS instrument allows performing Raman spectroscopy analysis together with Secondary Electron (SE) or Retrodispersive Electron (RE) imaging and EDS analysis inside the SEM chamber on the same spot areas selected previously. This fact is possible because the laser light and Raman signal are both transmitted between the Raman spectrometer and the SCA through $2 \mathrm{~m}$ fibre optic cables inside the SEM vacuum chamber. Two laser excitation sources are available at 785 and $514 \mathrm{~nm}$, and variable power at the sample can be applied.

With this configuration, first, a scanning chemical image of a micro area of the sample surface using SEM is performed. Then, it is possible to analyse that area identifying the presence/absence of chemical elements using EDS. Finally, by the Raman-SEM/EDS interface it is feasible to focus the laser beam on the point of
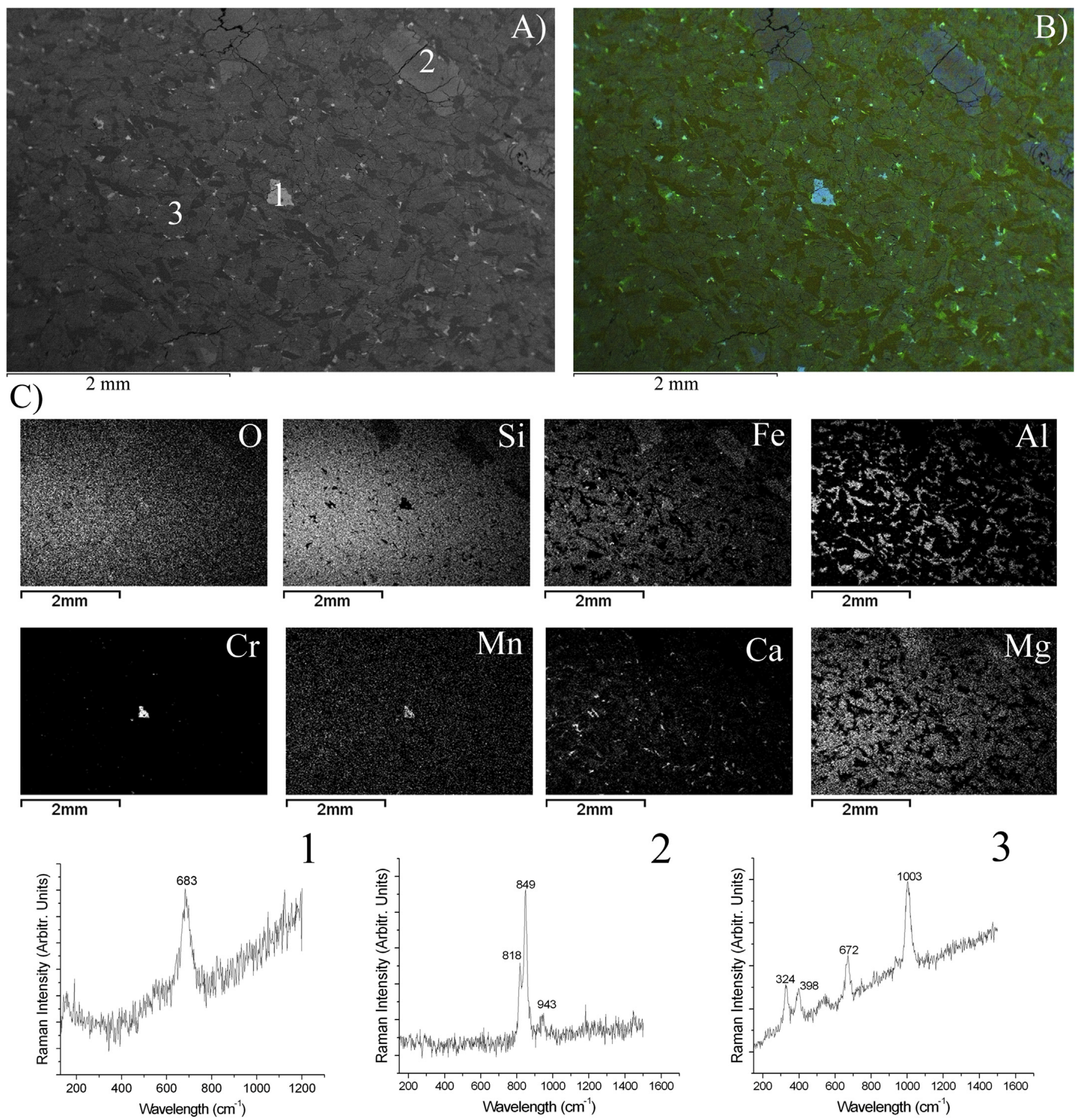

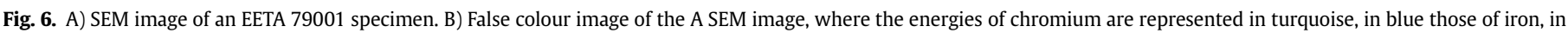

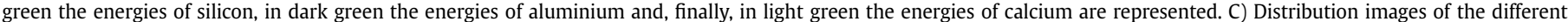

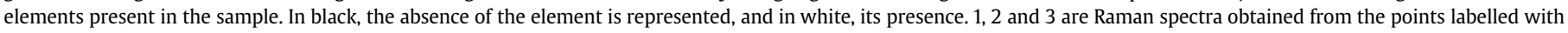
the same numbers in the SEM image A. 
interest to get Raman spectra without the need of moving the sample. Therefore, the Raman-SEM/EDS instrument allows getting elemental and molecular information of exactly the same point. The interface is useful to attain well defined objectives such as relating Raman displacements with slight differences in composition or to help the user identifying rare Raman spectra.

A typical Rama-SEM/EDS instrument has three units. The first unit is an EVO 40 EDS (Carl Zeiss NTS GmbH, Germany) coupled to an X-Max Energy-Dispersive X-Ray spectroscopy equipment (Oxford Instruments, UK) that is used for electron image acquisitions and elemental composition determinations. The SEM images are acquired at high vacuum employing an acceleration voltage of $20 \mathrm{kV}$. Magnifications up to 10000 are reached using an SE detector. The EDS (Oxford Instruments, UK), is used for elemental mapping, and the analyses are performed using an $8.5 \mathrm{~mm}$ working distance, a $35^{\circ}$ take-off angle and an acceleration voltage of $15-20 \mathrm{kV}$. For the SEM-EDS data collection the program INCA suite 4.13 (Microanalysis Suite, UK) is used. This software allows performing chemical maps of all elements present in the scanning image simultaneously. The plots appear in black and white, where the former represents the absence of an element and the latter its presence. Besides, there is the possibility to obtain false colour images of the analysed surface where the energies of each element are represented in different colours over the SEM image for a better visualization of the chemical maps.

The third unit is the Raman SCA interface (Renishaw, UK), that uses in-SEM retractable collection optic to introduce the laser light and focus it on the sample as well as to collect the Raman signal through the in-Via micro-Raman spectrometer. This Raman microspectrometer has a Peltier-cooled $\left(-70^{\circ} \mathrm{C}\right)$ detector. The spectrometer is provided by a 514 and $785 \mathrm{~nm}$ laser. The power applied is set at the source at a maximum of $50 \mathrm{~mW}$, while on the sample is always less than $20 \mathrm{~mW}$. The spectral resolution is around $1 \mathrm{~cm}^{-1}$. The software used for the data collection is Renishaw Wire 3.2. In order to avoid excessive noise in the spectra, the equipment is installed in an anti-vibratory table and in a temperature controlled room (around $20^{\circ} \mathrm{C}$ ). In spite of this, the collected spectra by Raman SCA are usually noisy and, therefore, long measures (up to $40 \mathrm{~s}$ and 40 accumulations) are needed to obtain a good signal to noise ratio. For conventional SEM/EDS analysis, the retraction mechanism of the Raman SCA is used to quickly move the optic away to a 'standby' position. This operation mode is used to set the positions of the trace elements in order to better focus with the SCA interface.

By using this Raman-SEM/EDS simultaneous combination of techniques, elemental and molecular information can be extracted at the same time in a couple of hours at maximum, like it was demonstrated with terrestrial analogues to meteorites [74]. In Fig. 6A, a SEM image can be seen, where different types of inclusions in a meteoritic matrix can be distinguished. The SEM image was obtained by collecting retro-dispersive electrons, which allows identifying heavy metals, since they appeared lighter in the SEM image. With only this information, it could be possible to detect some areas of interest, such as the inclusions present in the centre of the image. Besides, EDS analyses were performed to obtain the elemental characterization of the samples (see Fig. 6C). With this elemental data, false colour images can be created, where the energies of each detected elements is represented in different colours (see Fig. 6B). This representation makes much easier the interpretation of the results. With this image, the points to be analysed by Raman spectroscopy were selected.

As can be observed in the false colour image, three main areas can be discerned and, actually, these three were the areas of interest analysed by Raman spectroscopy (Fig. 6.1, 6.2 and 6.3). Spectrum 1 corresponds to a chromium oxide and was obtained by analysing the chromium rich area. Spectrum 2 is an olivine and corresponds to an iron and magnesium rich silicate. Finally, spectrum 3 was collected in aluminium and magnesium rich silicate and was identified as an augite. Both, elemental and molecular data are in agreement. By this means, the spatial molecular and elemental distribution of the meteorites and their heterogeneity was evaluated.

Fig. 7 shows a resuming scheme of the proposed methodology.
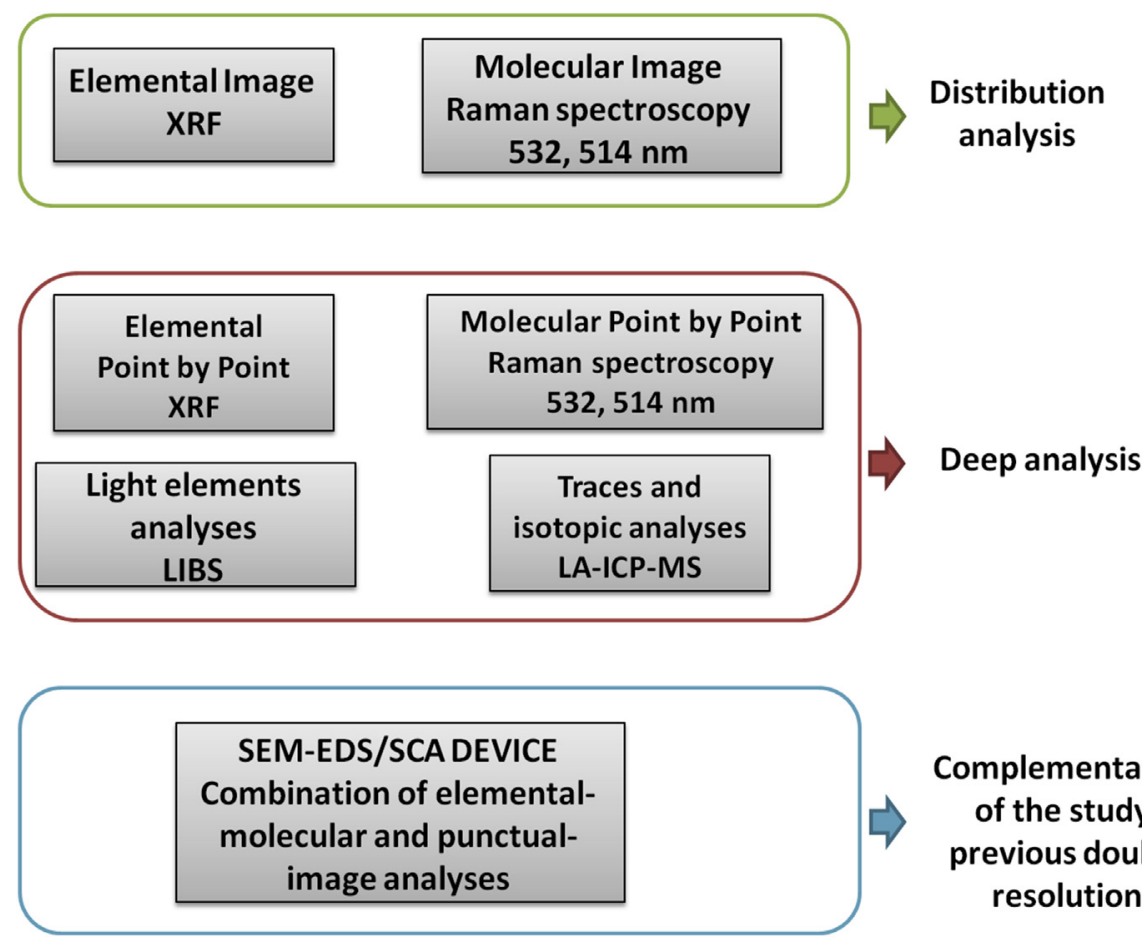

\author{
Complementation \\ of the study, \\ previous doubts \\ resolution
}

Fig. 7. Scheme of the proposed technology. 


\section{Conclusions}

Non-terrestrial samples are unique and each one could provide very valuable data. It is clear that analytical techniques play a key role in the Space research field.

Unfortunately, most of the studies performed up to this moment have been performed employing destructive analytic techniques. Due to this fact, several important samples have been destroyed and therefore, disappeared for next generations. An important effort has been performed to preserve the Cultural Heritage; however, this is not the case with Natural Heritage.

Clearly, the use of some of these destructive techniques, in certain cases, is mandatory. For instance, for organics detection and quantification, for now the most suitable procedure has been to perform GC-MS analyses. Nevertheless, with the evolution of the new generation non-destructive analytical techniques, there is no reason for the destruction of samples. Moreover, the consumption of chemicals and reactants is also avoided.

In order to solve this problem in the case of meteorites and analogues, a combination of techniques is proposed to perform advanced spectroscopic studies on such materials. It consists on combining Raman-SEM/EDS hyphenated instrument, the microXRF imaging and the LIBS analysis, always taking into account the advantages of other techniques for very defined purposes. With the Raman-SEM/EDS device, elemental and molecular microscopic characterization can be performed. Besides, by means of micro-XRF imaging, a general idea of the elemental composition of all the samples can be extracted, since sometimes the information given by SEM/EDS is very located and from a very small part of the whole sample. Besides, LA-ICP-MS is proposed for isotopic ratios studies and traces analyses. Finally, LIBS will be used for the quantification of elements in general, but specifically, light elements. The combination of LIBS and Raman could avoid the use of GC-MS.

It must be highlighted the importance of choosing the right wavelength for the Raman analyses. As it has been seen during this overview, we encourage using the 514 or $532 \mathrm{~nm}$ laser to avoid luminescence effect and to improve the acquisition of organic signals.

As complementary techniques we suggest to add Mössbauer and infrared spectroscopies to the proposed list. Mössbauer will be helpful in the characterization of metallic meteorites where the use of Raman is useless. In addition, IR would be the key for water or carbon dioxide search. Following this protocol, all the current objectives such as petrological characterization, searching water or water derived compounds, as well as life signals (biosignatures) can be fulfilled on meteorite and impact glasses.

\section{Acknowledgements}

This work has been financially supported through the project "Development of the Raman instrument for the ESA Mission Exomars2018: Science support, equipment testing and operation support" (Grant No. ESP2014-56138-C3-2-R) funded by the Spanish Ministry of Economy and Competitiveness (MINECO) and the European Regional Development Fund (FEDER). The mobility actions of researchers have been funded by the SUPERCAMCT Thematic Network (Grant. No. ESP2015-71965-REDT of MINECO). The sample of the EETA 79001 meteorite was kindly provided by the US Antarctic Meteorite Program. US Antarctic meteorite samples are recovered by the Antarctic Search for Meteorites (ANSMET) program which has been funded by NSF and NASA, and characterized and curated by the Department of Mineral Sciences of the Smithsonian Institution and Astromaterials Curation Office at NASA Johnson Space Center. Authors thank Raman-LASPEA Laboratory from the SGIker (UPV/EHU, MICINN, GV/EJ, ERDF and ESF) of the University of the Basque Country for their collaboration in the analyses.

\section{References}

[1] A.E. Rubin, J.N. Grossman, Meteorite and meteoroid: new comprehensive definitions, Meteorit. Planet. Sci. 45 (2010) 114-122.

[2] V. Crupi, A. Giunta, B. Kellett, F. Longo, G. Maisano, D. Majolino, A. Scherillo, V. Venuti, Handheld and non-destructive methodologies for the compositional investigation of meteorite fragments, Anal. Method 6 (2014) 6301-6309.

[3] John W. Webster, Chemical examination of a fragment of a meteor which fell in Maine, Philos. Mag. Ser. 1 (1823) 16-19.

[4] L.J. Spencer, Hoba (South-West Africa), the largest known meteorite, J. Mineral. Soc. 13 (1874) 1-18.

[5] J.L. Smith, Victoria meteoric iron, Am. J. Sci. 5 (1873) 107-109.

[6] C. Ma, J.R. Beckett, G.R. Rossman, Allendeite $\left(\mathrm{Sc}_{4} \mathrm{Zr}_{3} \mathrm{O}_{12}\right)$ and hexamolybdenum (Mo, Ru, Fe), two new minerals from an ultrarefractory inclusion from the Allende meteorite, Am. Mineral. 99 (2014) 654-666.

[7] C. Ma, A.N. Krot, Hutcheonite, $\mathrm{Ca}_{3} \mathrm{Ti}_{2}\left(\mathrm{SiAl}_{2}\right) \mathrm{O}_{12}$, a new garnet mineral from the Allende meteorite: an alteration phase in a Ca-Al-rich inclusion, Am. Mineral. 99 (2014) 667-670.

[8] I.K. Schuller, J.G. Ramirez, A.C. Basaran, M. Thiemens, S. Taylor, Search for superconductivity in extraterrestrial materials, Bull. Am. Phys. Soc. 59 (2014).

[9] R.W. Hilts, C.D.K. Herd, D.N. Simkus, G.F. Slater, Soluble organic compounds in the Tagish Lake meteorite, Meteorit. Planet. Sci. 49 (2014) 526-549.

[10] K.E. Smith, M.P. Callahan, P.A. Gerakines, J.P. Dworkin, C.H. House, Investigation of pyridine carboxylic acids in CM2 carbonaceous chondrites: potential precursor molecules for ancient coenzymes, Geochim. Cosmochim. Acta 136 (2014) $1-12$

[11] S. Pizzarello, L.A.J. Garvie, Sutter's Mill dicarboxylic acids as possible tracers of parent-body alteration processes, Meteorit. Planet. Sci. 49 (2014) 2087-2094.

[12] A.S. Burtona, S. Grunsfeld, J.E. Elsila, D.P. Glavin, J.P. Dworkin, The effects of parent-body hydrothermal heating on amino acid abundances in CI-like chondrites, Polar Sci. 8 (2014) 255-263.

[13] K. Kehm, E.H. Hauri, C.M. O'D Alexander, R.W. Carlson, High precision iron isotope measurements of meteoritic material by cold plasma ICP-MS, Geochim. Cosmochim. Acta 67 (2003) 2879-2891.

[14] X. Duan, M. Regelous, Rapid determination of 26 elements in iron meteorites using matrix removal and membrane desolvating quadrupole ICP-MS, J. Anal. At. Spectrom. 29 (2014) 2379-2387.

[15] L.J. Bridgestock, H. Williams, M. Rehkämper, F. Larner, M.D. Giscard, S. Hammonde, B. Coles, R. Andreasen, B.J. Wood, K.J. Theis, C.L. Smith, G.K. Benedix, M. Schönbächler, Unlocking the zinc isotope systematics of iron meteorites, Earth Planet. Sci. Lett. 400 (2014) 153-164.

[16] M. Martínez-Jiménez, C.E. Moyano-Cambero, J.M. Trigo-Rodríguez, J. AlonsoAzcárate, J. Llorca, Asteroid mining: mineral Resources in undifferentiated bodies from the chemical composition of carbonaceous chondrites, Assess. Mitig. Asteroid Impact Hazards 46 (2017) 73-101.

[17] R.F. Knacke, W. Kraetschmer, Infrared spectra of hydrated silicates, carbonaceous chondrites, and amorphous carbonates compared with interstellar dust absorptions, Astron. Astrophys. 92 (1980) 281-288.

[18] L.V. Moroz, M. Schmidt, U. Schade, T. Hiroi, M.A. Ivanova, Synchrotron-based infrared microspectroscopy as a useful tool to study hydration states of meteorite constituents, Meteorit. Planet. Sci. 41 (2006) 1219-1230.

[19] U. Chandra, G. Parthasarathy, N.V. Chandra Shekar, P.Ch. Sahu, X-ray diffraction, Mössbauer spectroscopic and electrical resistivity studies on Lohawat meteorite under high-pressure up to 9 GPa, Chem. Erde-Geochem. 73 (2013) 197-203.

[20] D.B. Tilley, A.W.R. Bevan, The Prolonged Weathering of Iron and Stony-iron Meteorites and Their Anomalous Contribution to the Australian Regolith, http://crcleme.org.au/Pubs/Monographs/regolith98/6-tilley\%26bevan.pdf

[21] J. Kennedy, M.N. Mautner, B. Barry, A. Markwitz, Microprobe analysis of brine shrimp grown on meteorite extracts, Nucl. Instrum. Methods B 260 (2007) 184-189.

[22] M. Noun, M. Roumie, T. Calligaro, B. Nsouli, R. Brunetto, D. Baklouti, L. d'Hendecourt, S. Della-Negra, On the characterization of the "Paris" meteorite using PIXE, RBS and micro-PIXE, Nucl. Instrum. Methods B 306 (2013) $261-264$.

[23] A. Vasilescu, B. Constantinescu, R. Bugoi, D. Ceccato, D. Grambole, F. Herrmann, Micro-elemental analysis of some Transylvanian meteorites and lunar samples, Nucl. Instrum. Methods B 267 (2009) 2233-2235.

[24] M.J. Bailey, K.T. Howard, K.J. Kirkby, C. Jeynes, Characterisation of inhomogeneous inclusions in Darwin glass using ion beam analysis, Nucl. Instrum. Methods B 267 (2009) 2219-2224.

[25] Y. Guan, G.R. Huss, L.A. Leshin, SIMS analyses of $\mathrm{Mg}, \mathrm{Cr}$, and Ni isotopes in primitive meteorites and short-lived radionuclides in the early solar system, Appl. Surf. Sci. 231-232 (2004) 899-902.

[26] S. Hu, Y. Lin, J. Zhang, J. Hao, L. Feng, L. Xu, W. Yang, J. Yang, NanoSIMS analyses of apatite and melt inclusions in the GRV 020090 Martian meteorite: hydrogen isotope evidence for recent past underground hydrothermal activity on Mars, Geochim. Cosmochim. Acta 140 (2014) 321-333. 
[27] C.W. Haberle, L.A. Garvie, K.J. Domanik, P.R. Christensen, Metamorphic Formation of Extraterrestrial Portlandite in the Sutter's Mill Meteorite (SM3), American Geophysical Union, Fall Meeting, 2013 abstract \#P31B-1809.

[28] Y.L. Wang, G. Crow, R. Levi-Setti, High lateral resolution SIMS mapping of meteorite chondrule, Nucl. Instrum. Methods B 10-11 (1985) 716-718.

[29] N. Sakamoto, S. Itoh, H. Yurimoto, Discovery of ${ }^{17,18}$ O-rich material from meteorite by direct-imaging method using stigmatic-SIMS and 2D ion detector, Appl. Surf. Sci. 255 (2008) 1458-1460.

[30] D. Wolf, H. Palme, The solar system abundances of phosphorus and titanium and the nebular volatility of phosphorus, Meteorit. Planet. Sci. 36 (2001) 559-571.

[31] A. Stracke, H. Palme, M. Gellissen, C. Münker, T. Kleine, K. Birbaum, D. Günther, B. Bourdon, J. Zipfel, Refractory element fractionation in the Allende meteorite: implications for solar nebula condensation and the chondritic composition of planetary bodies, Geochim. Cosmochim. Acta 85 (2012) 114-141.

[32] J. Aramendia, L. Gomez-Nubla, S. Fdz-Ortiz de Vallejuelo, K. Castro, X. Murelaga, J.M. Madariaga, New findings by Raman microespectroscopy of inclusions inside a Libyan desert glass, Spectrosc. Lett. 44 (2011) 521-525.

[33] L. Gomez-Nubla, J. Aramendia, A. Alonso-Olazabal, S. Fdez-Ortiz de Vallejuelo, K. Castro, L.A. Ortega, M.C. Zuluaga, X. Murelaga, J.M. Madariaga, Darwin impact glass study by Raman spectroscopy in combination with other spectroscopic techniques, J. Raman Spectrosc. 46 (2015) 913-919.

[34] K.C. Daviau, R.G. Mayne, A.J. Ehlman, An XRF study of meteorites, in: 43rd Lunar and Planetary Sciences Conference, vol. 1306, 2012.

[35] B. Laforce, S. Schmitz, B. Vekemans, J. Rudloff, J. Garrevoet, R. Tucoulou, F.E. Brenker, G. Martínez-Criado, L. Vincze, Nanoscopic X-ray fluorescence imaging of meteoritic particles and diamond inclusions, Anal. Chem. 86 (2014) 12369-12374.

[36] M. Gemelli, M. D'Orazio, L. Folco, Chemical analysis of iron meteorites using a hand-held X-ray fluorescence spectrometer, Geostand. Geoanal. Res. 39 (2015) 55-69.

[37] J. Brückner, G. Dreibus, R. Gellert, S. Squyres, H. Wänke, A. Yen, J. Zipfel, Mars exploration rovers: chemical composition by the APXS, in: J. Bell (Editor), Martian Surface, Cambridge University Press, 2008.

[38] J.L. Campbell, J.A. Maxwell, S.M. Andrushenko, S.M. Taylor, B.N. Jones, W. Brown-Bury, A GUPIX-based approach to interpreting the PIXE-plus-XRF spectra from the Mars Exploration Rovers: I. Homogeneous standards, Nucl. Instrum. Methods B 269 (2011) 57-68.

[39] J. Yang, J.I. Goldstein, E.R.D. Scott, J.R. Michael, P.G. Kotula, A. Grimberg, I. Leya, Thermal and collisional history of Tishomingo iron meteorite: more evidence for early disruption of differentiated planetesimals, Geochim. Cosmochim. Acta 124 (2014) 34-53.

[40] J. Garcia-Guinea, L. Tormo, A. Rubio Ordoñez, O. Garcia-Moreno, Nondestructive analyses on a meteorite fragment that fell in the Madrid city centre in 1896, Talanta 114 (2013) 152-159.

[41] Ph. Gillet, J.A. Barrat, Th. Heulin, W. Achouak, M. Lesourd, F. Guyot, $\mathrm{K}$. Benzerara, Bacteria in the Tatahouine meteorite: nanometric-scale life in rocks, Earth Planet. Sci. Lett. 175 (2000) 161-167.

[42] K.H. Joy, A. Nemchin, M. Grange, T.J. Lapen, A.H. Peslier, D.K. Ross, M.E. Zolensky, D.A. Kring, Petrography, geochronology and source terrain characteristics of lunar meteorites Dhofar 925, 961 and Sayh al Uhaymir 449, Geochim. Cosmochim. Acta 144 (2014) 299-325.

[43] E.L. Walton, Shock metamorphism of Elephant Moraine A79001: implications for olivine-ringwoodite transformation and the complex thermal history of heavily shocked Martian meteorites, Geochim. Cosmochim. Acta 107 (2013) 299-315.

[44] Ph. Gillet, J.A. Barrat, E. Deloule, M. Wadhwa, A. Jambon, V. Sautter, B. Devouard, D. Neuville, K. Benzerara, M. Lesourd, Aqueous alteration in the Northwest Africa 817 (NWA 817) Martian meteorite, Earth Planet. Sci. Lett. 203 (2002) 431-444.

[45] J.I. Goldsteina, G.R. Hussb, E.R.D. Scott, Ion microprobe analyses of carbon in $\mathrm{Fe}-\mathrm{Ni}$ metal in iron meteorites and mesosiderites, Geochim. Cosmochim. Acta 200 (2017) 367-407.

[46] P.S. Athiray, M. Sudhakar, M.K. Tiwari, S. Narendranath, G.S. Lodha, S.K. Deb, P. Sreekumar, S.K. Dash, Experimental validation of XRF inversion code for Chandrayaan, Planet. Space Sci. 89 (2013) 183-187.

[47] G.S. Senesi, Laser-Induced Breakdown Spectroscopy (LIBS) applied to terrestrial and extraterrestrial analogue geomaterials with emphasis to minerals and rocks, Earth Sci. Rev. 139 (2014) 231-267.

[48] N.L. Lanza, R.C. Wiens, H.E. Newsom, R.E. McInroy, S.M. Clegg, S.C. Bender, A preliminary examination of meteorites with laser-induced breakdown spectroscopy (LIBS), in: 43rd Lunar and Planetary Science Conference, 2012 abstract\#2780.

[49] D. Ozdin, J. Plavcan, M. Hornackova, P. Uher, V. Porubcan, P. Veis, J. Rakovsky, J. Toth, P. Konecny, J. Svoren, Mineralogy, petrography, geochemistry, and classification of the Kosice meteorite, Meteorit. Planet. Sci. 50 (2015) 864-879.

[50] R.C. Wiens, S. Maurice, J. Lasue, O. Forni, R.B. Anderson, S. Clegg, S. Bender, D. Blaney, B.L. Barraclough, A. Cousin, L. Deflores, D. Delapp, M.D. Dyar, C. Fabre, O. Gasnault, N. Lanza, J. Mazoyer, N. Melikechi, P.-Y. Meslin, H. Newsom, A. Ollila, R. Perez, R.L. Tokar, D. Vaniman, Pre-flight calibration and initial data processing for the ChemCam laser-induced breakdown spectroscopy instrument on the Mars Science Laboratory rover, Spectrochim. Acta B 82 (2013) 1-27.

[51] M. Dell'Aglio, A. DeGiacomo, R. Gaudiuso, O. DePascale, S. Longo, Laser Induced Breakdown Spectroscopy of meteorites as a probe of the early solar system, Spectrochim. Acta B 101 (2014) 68-75.

[52] S.R. Gordon, H.E. Newsom, C.B. Agee, S.M. Clegg, J. Lasue, R.C. Wiens, A.R. Santos, A preliminary study comparing LIBS on Martian meteorite NWA 7034 and ChemCam data, Eighth Int. Conf. Mars 1047 (2014).

[53] NASA Webpage, News 07.31, 2013. http://mars.nasa.gov/mars2020/news/ whatsnew/index.cfm?FuseAction $=$ ShowNews $\&$ NewsID $=1684$.

[54] B. Fernandez, F. Claverie, C. Pecheyran, O.F.X. Donard, Direct analysis of solid samples by fs-LA-ICP-MS, TrAC - Trend Anal. Chem. 26 (2007) 951-966.

[55] J.D. Woodhead, M.S.A. Horstwood, J.M. Cottle, Restricted access advances in isotope ratio determination by LA-ICP-MS, Am. Mineral. Soc., https://doi.org/ 10.2113/gselements.12.5.317.

[56] E.L. Sprenkel-Segel, S.S. Hanna, Mössbauer analysis of iron in stone meteorites, Geochim. Cosmochim. Acta 28 (1994) 1913-1931.

[57] C. Van Cromphaut, V.G. De Resende, E. De Grave, R.E. Vandenberghe, Mössbauer study of Meridiani Planum, the first iron-nickel meteorite found on the surface of Mars by the MER Opportunity, Meteorit. Planet. Sci. 42 (2007) 2119-2123.

[58] M. Yesiltas, Y. Kebukawa, R.E. Peale, E. Mattson, C.J. Hirschmugl, P. Jenniskens, Infrared imaging spectroscopy with micron resolution of Sutter's Mill meteorite grains, Meteorit. Planet. Sci. 49 (2014) 2027-2037.

[59] L. Gomez-Nubla, J. Aramendia, S. Fdez-Ortiz de Vallejuelo, A. Alonso-Olazabal K. Castro, M.C. Zuluaga, L.A. Ortega, X. Murelaga, J.M. Madariaga, Multispectroscopic methodology to study Libyan desert glass and its formation conditions, Anal. Bional. Chem. 409 (2017) 3597-3610.

[60] S. Maurice, R.C. Wiens, S. Le Mouélic, R. Anderson, O. Beyssac, L. Bonal, S. Clegg, L. DeFlores, G. Dromar, W. Fischer, O. Forni, O. Gasnault, J. Grotzinger, J. Johnson, J. Martinez-Frias, N. Mangold, S. McLennan, F. Montmessin, F. Rull, S. Sharma, The SuperCam instrument for the Mars 2020 rover, in: European Planetary Science Congress, vol. 10, 2015. EPSC2015-P2185.

[61] C. Pilorget, J.P. Bibring, the MicrOmega team, The MicrOmega instrument onboard Exomars and future missions: an IR hyperspectral microscope to analyze samples at the grain scale and characterize early Mars processes, in: Third Conference on Early Mars, 7006, 2012.

[62] A. Wang, K. Kuebler, B. Jolliff, L.A. Haskin, Mineralogy of a Martian meteorite as determined by Raman spectroscopy, J. Raman Spectrosc. 35 (2004) 504-514.

[63] F. Rull, J. Martinez-Frias, A. Sansano, J. Medina, H.G. Edwards, Comparative micro-Raman study of the Nakhla and Vaca Muerta meteorites, J. Raman Spectrosc. 35 (2004) 497-503.

[64] C. El Amri, M.H. Baron, M.C. Maurel, Adenine adsorption on and release from meteorite specimens assessed by surface-enhanced Raman spectroscopy, J. Raman Spectrosc. 35 (2004) 170-177.

[65] S. Caporali, V. Moggi-Cecchi, M. Muniz-Miranda, M. Pagliai, G. Pratesi, V. Schettino, SERS investigation of possible extraterrestrial life traces: Experimental adsorption of adenine on a Martian meteorite, Meteorit. Planet. Sci. 47 (2012) 853-860.

[66] K.E. Kuebler, B.L. Jolliff, A. Wang, L.A. Haskin, Extracting olivine (Fo-Fa) compositions from Raman spectral peak positions, Geochim. Cosmochim. Acta 70 (2006) 6201-6222.

[67] T. Frosch, N. Tarcea, M. Schmitt, H. Thiele, F. Langenhorst, J. Popp, UV Raman imaging-a promising tool for astrobiology: comparative Raman studies with different excitation wavelengths on SNC Martian meteorites, Anal. Chem. 79 (2007) 1101-1108.

[68] I. Torre-Fdez, J. Aramendia, L. Gomez-Nubla, K. Castro, J. M. Madariaga, Geochemical study of the Northwest Africa 6148 Martian meteorite and its terrestrial weathering processes, J. Raman Spectrosc., https://doi.org/10.1002/ jrs.5148.

[69] A. Wang, R.L. Korotev, B.L. Jolliff, Z. Ling, Raman imaging of extraterrestrial materials, Planet. Space Sci. 112 (2015) 23-34.

[70] G. Lopez-Reyes, F. Rull, G. Venegas, F. Westall, F. Foucher, N. Bost, A. Sanz, A. Catalá -Espí, A. Vegas, I. Hermosilla, A. Sansano, J. Medina, Analysis of the scientific capabilities of the ExoMars Raman laser spectrometer instrument, Eur. J. Mineral. 25 (2013) 721-733.

[71] J. Aramendia, L. Gomez-Nubla, L. Bellot-Gurlet, K. Castro, G. Arana, J.M. Madariaga, Bioimpact on weathering steel surfaces: oxalates formation and the elucidation of their origin, Int. Biodeter. Biodegrad. 104 (2016) 59-66.

[72] J. Aramendia, L. Gomez-Nubla, K. Castro, J.M. Madariaga, Structural and chemical analyzer system for the analysis of deposited airborne particles and degradation compounds present on the surface of outdoor weathering steel objects, Microchem. J. 123 (2015) 267-275.

[73] C. Cardell, I. Guerra, An overview of emerging hyphenated SEM-EDX and Raman spectroscopy systems: applications in life, environmental and materials sciences, TrAC - Trend Anal. Chem. 77 (2016) 156-166.

[74] L. Gomez-Nubla, J. Aramendia, S. Fdez-Ortiz de Vallejuelo, K. Castro, J.M. Madariaga, From Portable to SCA Raman devices to characterize harmful compounds contained in used black slag produced in electric arc furnace of steel industry, J. Raman Spectrosc. 44 (2013) 1163-1171. 